\title{
To the Editor-
}

In my recent $I O$ article ("The Creation and Maintenance of National Boundaries in Africa," International Organization, vol. 43 , no. 4 , 1989, pp. $673-92$ ), the views of Saadia Touval were misapplied. Rather than local political factors being completely ignored in boundary creation, he argues that disregard of local political circumstances was "not universal" and that sometimes local circumstances did affect the design of borders. See Saadia Touval, "Treaties, Borders and the Partition of Africa," The Journal of African History, vol. 7, no. 2, 1966, pp. 279-92. 

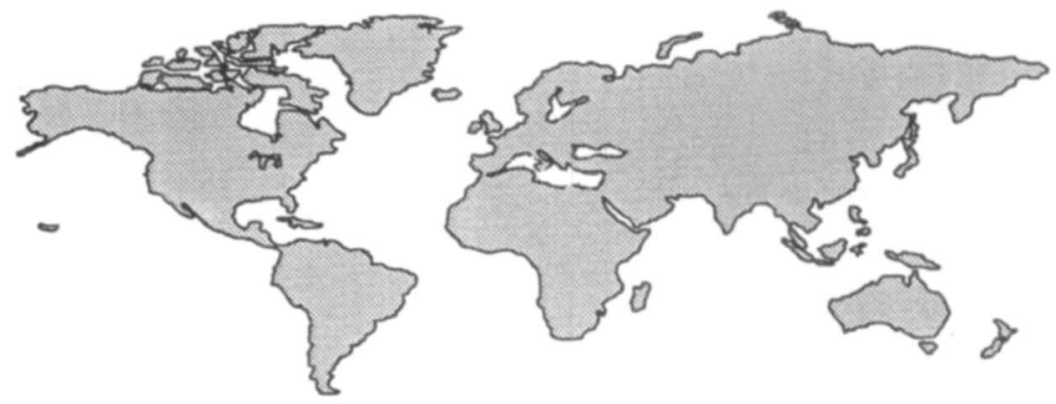

\section{Turbulence in World Politics}

\section{A Theory of Change and Continuity}

\section{James N. Rosenau}

In this ambitious work a leading scholar undertakes a full-scale reconceptualization of international relations. Turbulence in World Politics is an entirely new formulation that accounts for the persistent turmoil of today's world, even as it also probes the impact of the microelectronic revolution, the postindustrial order, and the many other fundamental political, economic, and social changes under way since World War II.

'Like so many of Rosenau's contributions to the field, this volume contains key insights into major conceptual issues and a flair for words that sweeps the reader along from concept to concept, argument to argument. Not all will accept Rosenau's premises, but the challenge they provide is a significant contribution to the discipline."

-Dina A. Zinnes, University of Illinois

'Rosenau's new work is an imaginative leap into world politics in the twenty-first century. There is much here to challenge traditional thought of every persuasion."

-Michael Brecher, McGill University

Paper. \$14.50 ISBN 0-691-02308-5

Cloth: $\$ 45.00$ ISBN 0-691-07820-3

AT YOUR BOOKSTORE OR 